\title{
Ontogenies of phototactic behavior and metamorphic competence in larvae of three species of Bugula (Bryozoa)
}

\author{
Dean E. Wendt ${ }^{\mathrm{a}}$ and Robert M. Woollacott
}

Department of Organismic and Evolutionary Biology, Harvard University, Cambridge, Massachusetts 02138, USA

\begin{abstract}
The free swimming larvae of many marine invertebrates actively respond to light. Light cues can be used to regulate position in the water column and to facilitate encountering sites suitable for metamorphosis. We examined the ontogeny of larval phototaxis and the ontogeny of metamorphic competency in larvae from three congeneric species of bryozoans. Larvae of Bugula neritina are positively phototactic on emergence from the brood chamber, whereas larvae of $B$. simplex and B. stolonifera appear initially photoneutral when populations of larvae are examined. Larvae of all three species become photonegative with time. Temporally coincident with this change to negative phototaxis is an increase in the competency of larvae to initiate metamorphosis. This observation suggests that these events are either physiologically linked or co-occurring, but independent developmental processes. We tested these hypotheses by artificially changing the sign of phototaxis from positive to negative using $10^{-5} \mathrm{M}$ bathapplied 5-hydroxytryptamine (5HT) in larvae of $B$. neritina that were swimming for $1 \mathrm{~h}$. Larvae that were photopositive and 1-h-old did not metamorphose at levels significantly different from larvae that were 1-h-old and treated with 5HT (i.e., young, photonegative larvae). Additionally, photopositive larvae which were swimming for $4 \mathrm{~h}$ initiated metamorphosis at rates nearly identical to photonegative larvae of the same age. Our data document that in larvae of $B$. neritina the changes in sign of phototaxis and levels of metamorphic competency are independent developmental events that occur in temporal coincidence. The concurrent timing of these two pathways may have been synchronized through selective processes resulting in a tight coupling between arrival at potentially suitable sites for metamorphosis and ability to respond to metamorphic cues.
\end{abstract}

Additional key words: bryozoans, phototaxis

Many benthic marine invertebrates have as part of their life cycle a planktonic larval stage. Successful completion of the life cycle requires return to a suitable benthic habitat. Larvae utilize a variety of physical and biological cues to facilitate location of sites favorable for subsequent adult life (e.g., Pawlik 1992; Young 1995). Light is one such physical signal. Light is a ubiquitous vector in relatively shallow waters that exhibits both spatial and temporal variation. The temporal variation can be highly predictable (sunrise and sunset) or highly variable (changes in cloud cover). Responses to light are one potentially useful means of regulating vertical orientation and position in the water column (e.g., Thorson 1964; Clarke 1970; Cronin \& Forward 1979; Sulkin 1984; Forward 1988; Barile et al. 1994; Young 1995). Additionally, in the case of meroplanktonic larvae, phototactic responses can con- tribute to delivery of larvae to benthic sites suitable for metamorphosis (e.g., McDougall 1943; Ryland 1960; Crisp 1974; Young \& Chia 1982; Olson 1985; Dirnberger 1993).

Thorson's (1964) seminal work was the first detailed comparative study of the ontogeny of phototaxis across several phyla of benthic marine invertebrates. He observed that $82 \%$ of 141 species from 11 phyla had early-stage larvae that were initially photopositive. Of these, $76 \%$ became photonegative before the conclusion of larval life. Thorson suggested that earlystage positive phototaxis increases the chances that larvae will be transported into the water column and hence away from conspecific adults and benthic predators. In the water column, larvae can be passively dispersed by currents, and feeding larvae can have access to more abundant populations of phytoplankton. Larvae that change to photonegative with time will then likely move to benthic sites, which is essential for completion of the life cycle. 
In many species, larval development can consist of three phases with regard to the ability of individuals to metamorphose when presented with an appropriate cue: (1) a precompetent phase, during which larvae cannot metamorphose; (2) a competent phase when larvae are able to metamorphose; and, in some species with non-feeding larvae, (3) a postcompetent phase, where larvae again cannot metamorphose. The duration of each of these phases and the factors that control the onset and maintenance of competence in larvae is quite variable among species (e.g., Hadfield 1984; Coon et al. 1990; Pechenik 1990; Gibson 1995; Pechenik et al. 1995, 1996; Wendt 1996; Zaslow \& Benayahu 1996; Pechenik \& Qian 1998). The precompetent phase temporally parallels, at least initially, the photopositive period of larval life. As development proceeds, the sign of phototaxis changes and larvae also become competent. In some species, these changes occur coincidentally (e.g., Miller \& Hadfield 1986; Ramirez \& Cancino 1991). This observation suggests that these events are either physiologically linked or cooccurring, but independent, developmental processes.

Miller \& Hadfield (1986) were the first investigators to explicitly examine the relationship between ontogeny of phototaxis and ontogeny of metamorphic competency. Using larvae of the gastropod Phestilla sibogae, they found an inverse relationship between the onset of competency and change in sign of phototaxis. In a second experiment, Miller \& Hadfield found no significant difference, however, in the occurrence of metamorphosis by larvae in lighted, compared to dark, ends of their experimental chambers. These results suggest that, in larvae of $P$. sibogae, the phototaxis and competency pathways are parallel, but not linked.

We chose to examine the ontogenies of phototaxis and metamorphic competence in larvae from three species of the marine bryozoan Bugula. In particular, $B$. neritina presents a useful species to dissect the interdependence of phototaxis and competency; first, it is possible to chemically induce "young" photopositive larvae to change into "young" photonegative larvae during the naturally occurring precompetent period. Therefore, larval age can be separated from the ontogenetic trajectories of phototaxis and competency (Pires \& Woollacott 1997). Second, embryonic stages are brooded, and release of larvae can be manipulated by changes in the light regime to obtain large numbers of larvae of known age (Woollacott 1984). Third, larvae are anenteric and have swimming periods lasting from hours to a maximum of 1-2 days (Wendt 1996). Fourth, metamorphic competence is easily assayed using elevated concentrations of $\mathrm{KCl}$ (Wendt \& Woollacott 1995).

In our study, we: (1) describe a new apparatus suit- able for measuring the photoresponses of larvae and small invertebrates which exposes organisms to a large gradient of diffuse light; (2) examine the synchronization and physiological interdependence of the onset of metamorphic competence and change in sign of phototaxis in larvae of $B$. neritina; and (3) assess in comparison the ontogenies of phototaxis and competency in two additional congeners, $B$. simplex and $B$. stolonifera.

\section{Methods}

\section{Collection and maintenance of colonies and larvae}

Sexually mature colonies of Bugula neritina were collected from floating docks in the Indian River, Fort Pierce, Florida during March, 1997. For a separate set of experiments, colonies of $\boldsymbol{B}$. neritina were also collected off carpet "bumpers" on the sides of docks at Kewalo Basin Marina, Honolulu, Hawaii, during the months of May-August, 1997. Gravid colonies of $B$. simplex and $B$. stolonifera were collected from floating docks in Eel Pond, Woods Hole, Massachusetts during July and August 1997. Colonies collected in Florida were maintained at the Smithsonian Marine Station at Link Port in plastic boxes that were continuously supplied with habitat seawater; those collected in Hawaii were maintained at the Kewalo Marine Laboratory in flowing seawater; and those collected in Woods Hole were maintained at Harvard University in plastic aquaria with water collected from the habitat. Colonies were kept in the dark and no supplemental food was provided.

Attachment (often referred to as settlement in the literature) of bryozoan larvae is integrally coupled to metamorphosis in that it is irreversible and marked by eversion of the metasomal (internal) sac; the first morphogenetic movement of metamorphosis in bryozoans (Zimmer \& Woollacott 1977). Thus, attachment in bryozoans is not exclusively a behavioral change associated with substratum exploration. We will hereafter refer to this process as the initiation (or induction) of metamorphosis.

In all experiments, larvae were obtained by exposing dark-adapted colonies to fluorescent illumination. Larvae used were from colonies maintained in the laboratory $<5$ days, and they were released from several colonies simultaneously to insure a heterogeneous population for experiments. Metamorphic competence was evaluated by assaying for eversion of the internal sac after exposure for $0.5 \mathrm{~h}$ to $10 \mathrm{mM}$ supplemental $\mathrm{KCl}$ (Wendt \& Woollacott 1995). Because the time of fertilization cannot be determined for individual larvae, minor differences in the developmental stage of larvae are not possible to discern. Thus, it is possible 


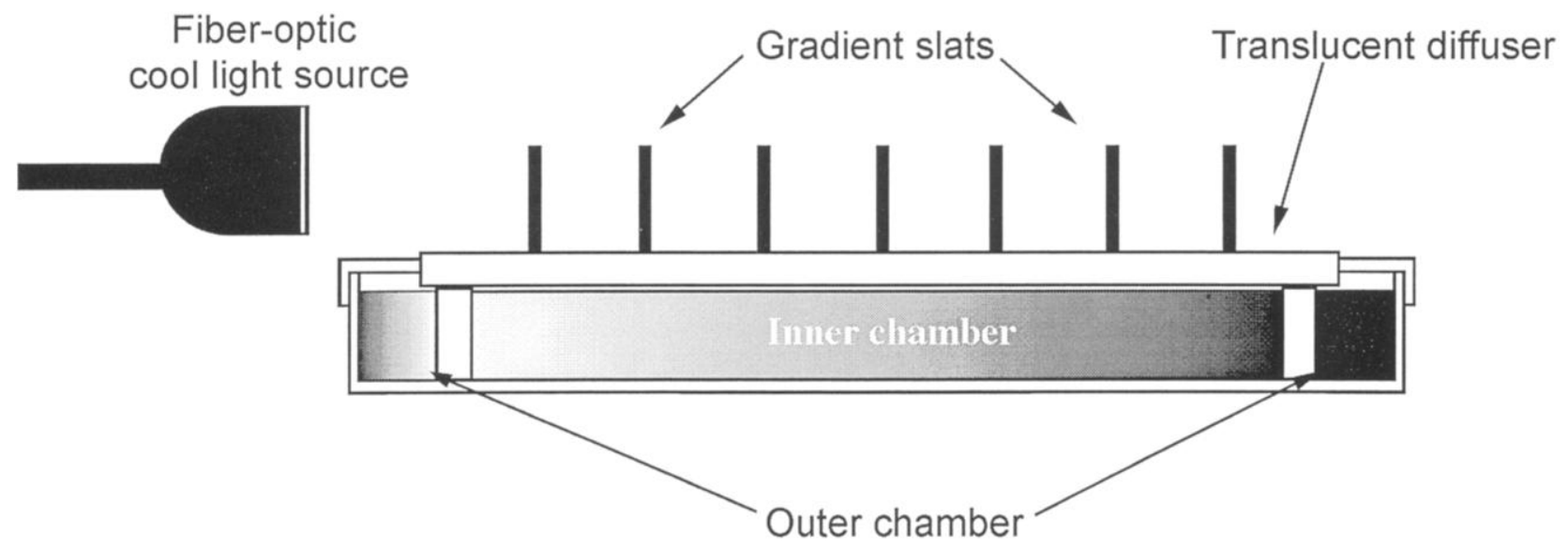

Fig. 1. The apparatus used in experiments for measuring phototaxis of individual larvae. The apparatus consists of an inner and outer chamber. The roof of the inner chamber is a translucent piece of Lucite that acts as a diffuser. The floor of the inner chamber is a grid that allows identification of larval position. The outer chamber is filled with water and serves to diminish any internal reflections that might affect larval behavior. A horizontal gradient of light is established by the slats that sit on top of the diffuser. There is $\sim 2$ orders of magnitude difference in the amount of light from the front to the back of the chamber $\left(110 \mu \mathrm{mol}\right.$ photons $\mathrm{m}^{-2} \mathrm{~s}^{-1}$ to $<1 \mu \mathrm{mol}$ photons $\left.\mathrm{m}^{-2} \mathrm{~s}^{-1}\right)$. See methods for dimensions and further details.

that developmental stage may differ slightly between larvae released at the same time.

\section{Interdependence of phototaxis sign and onset of metamorphic competence in $B$. neritina}

In experiments done in Hawaii, sign of phototaxis and metamorphic competence were examined by monitoring percent metamorphosis in groups of larvae in treatment vessels. In the Florida experiments, phototaxis and competence of individuals were followed rather than collecting data from batches of larvae. The protocols also involved different light regimes and experimental chambers.

In the first experiment done in Hawaii, larvae that were photopositive and $0.5 \mathrm{~h}$ old were collected by taking individuals from the lighted side of a dish $8 \mathrm{~cm}$ from a bank of two 60-cm Sylvania (F20T12/cw) Cool White ${ }^{\circledR}$ fluorescent bulbs. Larvae were transferred by pipet from glass bowls containing parent colonies to separate treatment dishes. Batches of larvae that were photopositive and $0.5 \mathrm{~h}$ old were induced to switch to photonegative by bath application of $10^{-5} \mathrm{M}$ 5hydroxytryptamine hydrochloride (5HT or serotonin, Sigma Chemical) (Pires \& Woollacott 1997) and the percentage of individuals metamorphosing at $1 \mathrm{~h}$ was compared with controls. Larvae were divided into four treatment groups: (1) larvae that were photopositive and $0.5 \mathrm{~h}$ old swimming in seawater; (2) larvae that were photopositive and $0.5 \mathrm{~h}$ old swimming in seawater with $10 \mathrm{mM}$ excess $\mathrm{KCl}$; (3) larvae that were induced to be photonegative and $0.5 \mathrm{~h}$ old swimming in seawater; and (4) larvae that were induced to be photonegative and $0.5 \mathrm{~h}$ old swimming in seawater with $10 \mathrm{mM}$ excess $\mathrm{KCl}$. Metamorphosis was assayed at $1 \mathrm{~h}$ as described above. The experiment, including all treatment groups, was replicated 15 times with 1027 larvae per treatment for each replicate. Experiments were done in three arrays with larvae obtained from two collections of adults.

A second experiment in Hawaii was designed to compare metamorphic competency of larvae that were $1 \mathrm{~h}$ old and photopositive, with larvae that were $4 \mathrm{~h}$ old and photopositive and larvae that $4 \mathrm{~h}$ old and "naturally occurring" photonegative. Again, groups rather than individual larvae were assayed and larvae were transferred to treatment dishes by pipet. The light regime was as described above. The experiment contained three treatment groups: (1) $0.5 \mathrm{~h}$ old larvae with $0.5 \mathrm{~h}$ exposure to $10 \mathrm{mM} \mathrm{KCl}$; (2) $3.5 \mathrm{~h}$ old larvae that were photopositive with $0.5 \mathrm{~h}$ exposure to $10 \mathrm{mM}$ $\mathrm{KCl}$; and (3) $3.5 \mathrm{~h}$ old larvae that were photonegative with $0.5 \mathrm{~h}$ exposure to $10 \mathrm{mM} \mathrm{KCl}$. The experiment, including all treatment groups, was replicated 45 times with 9-16 larvae per treatment for each replicate. Experiments were done in four batches using larvae obtained from two collections of colonies.

In a separate set of experiments performed in Florida, photoresponses of individual larvae were tested using the apparatus described below (Fig. 1). The photoresponses of larvae were tested as they emerged from brood chambers. Thus, larvae were several minutes "old" for $0 \mathrm{~h}$ time points in experiments. In each case, releases lasted for a maximum of $0.5 \mathrm{~h}$. Larvae were tested for their photoresponse at $2 \mathrm{~h}$ and $4 \mathrm{~h}$ after 
the start of the release. At each sampling time, $\sim 12-$ 30 larvae were tested for their phototactic response and metamorphic competence. An individual larva was removed from the release dish (with a pipette) and placed in the center of the phototaxis chamber, which was illuminated with diffuse, directional light. The larva was allowed to swim for $\sim 10-15$ seconds in the gradient and then its position was recorded. Larval response was determined after $10-15 \mathrm{~s}$ to prevent possible behavioral effects associated with contacting a wall of the chamber. To test for metamorphic competence, larvae were transferred to 5-ml polystyrene weigh boats filled with $10 \mathrm{mM} \mathrm{KCl}$ in seawater; the percentage of larvae having initiated metamorphosis, as judged by irreversible eversion of the internal (metasomal) sac, was counted after $0.5 \mathrm{~h}$.

\section{Ontogeny of phototaxis and metamorphic competence in $B$. simplex and $B$. stolonifera}

The protocol for assessing photoresponse and competence was the same as that described for examining responses of individual larvae of $B$. neritina from Florida. In this series of experiments, however, photoresponse and metamorphic competence were tested at 2 $\mathrm{h}$ time intervals for the first $10 \mathrm{~h}$ of larval swimming. Additionally, metamorphic competence was determined after 24,36 , and $48 \mathrm{~h}$ of larval swimming. A total 40-45 larvae (collected from 4 different assemblages of colonies) were tested at each time point for photoresponse and metamorphic competence.

\section{Description of apparatus used to measure phototaxis of individual larvae}

Phototactic behavior of individual larvae was measured using an apparatus that creates a diffuse gradient of white light (Fig. 1). Illumination was provided by a Schott ${ }^{\text {(ND }}$ fiber-optic cold light source (model KL1500), outfitted with a $15 \mathrm{~V} / 150 \mathrm{~W}$ ellipsoid halogen reflector bulb. The chamber was constructed using a plastic Petri dish, $14 \mathrm{~cm}$ in diameter. Inside the bottom portion of the Petri dish, an $8 \mathrm{~cm} \times 9 \mathrm{~cm}$ rectangle was constructed out of clear Lucite ${ }^{\mathbb{T N}}$. The inner chamber had as its floor a grid with linear coordinates, which was used to identify the location of larvae in the chamber. The internal and external chambers contained seawater, thus minimizing any internal reflections on the Lucite ${ }^{\text {TIM }}$ walls. A diffuser was made by inserting a $9 \mathrm{~cm} \times 10 \mathrm{~cm}$ rectangle of translucent piece of Lucite $\sqrt{\sqrt{N M}}$ in the top of the Petri dish; the translucent Lucite formed a seal with the inner chamber and thus only diffuse light entered the chamber. A gradient of light was established by placing a series of vertical slats $(9 \mathrm{~cm}$ wide $\times 2 \mathrm{~cm}$ tall $)$ at $\sim 1.5 \mathrm{~cm}$ intervals starting at the light source and continuing to the end of the chamber. The gradient of light intensity was $\sim 2$ orders of magnitude, $\sim 110 \mu \mathrm{mol}$ photons $\mathrm{m}^{-2}$ $\mathrm{s}^{-1}$ at the brightest portion of the chamber to $<1 \mu \mathrm{mol}$ photons $\mathrm{m}^{-2} \mathrm{~s}^{-1}$ at the darkest. The light gradient was established in a horizontal direction to remove confounding behavioral effects associated with geotaxis, which has been demonstrated in larvae of Bugula neritina (Pires \& Woollacott 1983). The outer chamber, the lid, and the diffuser slats were painted with flat black paint for maximal light absorbance.

\section{Treatment of data for tests of batch larvae}

Number of larvae that metamorphosed was converted to a percentage for each condition. The percentages were square-root transformed to remove heteroscedasticity. For the "serotonin" experiment, the data met the assumptions for Analysis of Variance (ANOVA), and thus a Model I (fixed factor) one-way factorial design was used. Fisher's Protected Least Square Difference (PLSD) was use to identify differences between classes. In the "naturally-aged" experiment, transformations did not remove the heteroscedasticity; in this case, a non-parametric Kruskal-Wallis test was used in lieu of ANOVA. P-values $\leq .05$ were considered significant.

\section{Treatment of data for tests of individual larvae}

Linear coordinates used to describe the position of larvae in the chamber were converted to polar coordinates, providing an angle of deflection from the light source $(\theta)$ and distance (i.e., radius) from the central point of the chamber. Theta of $0^{\circ}$ indicates that the larva swam directly toward the brightest portion of the chamber. Conversely, $\theta$ of $180^{\circ}$ indicates that a larva swam directly toward the darkest portion of the chamber. Circular statistics were used to calculate the mean angle of dispersion $(\delta)$ at each time point and the value " $r$ ", a measure of the dispersion of the data and which ranges from 0 to 1 . For example, if the distribution of the larvae was random, $r=0$; conversely, if every larva swam to exactly the same point in a trial, then $r=1$. The statistic " $z$ " was used to determine the significance of the mean angle $(\delta)$. Values of $\mathrm{z}$ greater than 2.9 are significant at $\mathrm{p}=.05$ (Zar 1996).

\section{The "pipette effect"}

Ryland (1960) found that pipetting larvae of bryozoans caused a precipitous change from photopositive to photonegative. We tested the "pipette effect" using larvae of $B$. stolonifera by pipetting individual larvae and looking for a change in sign of phototaxis. We did 

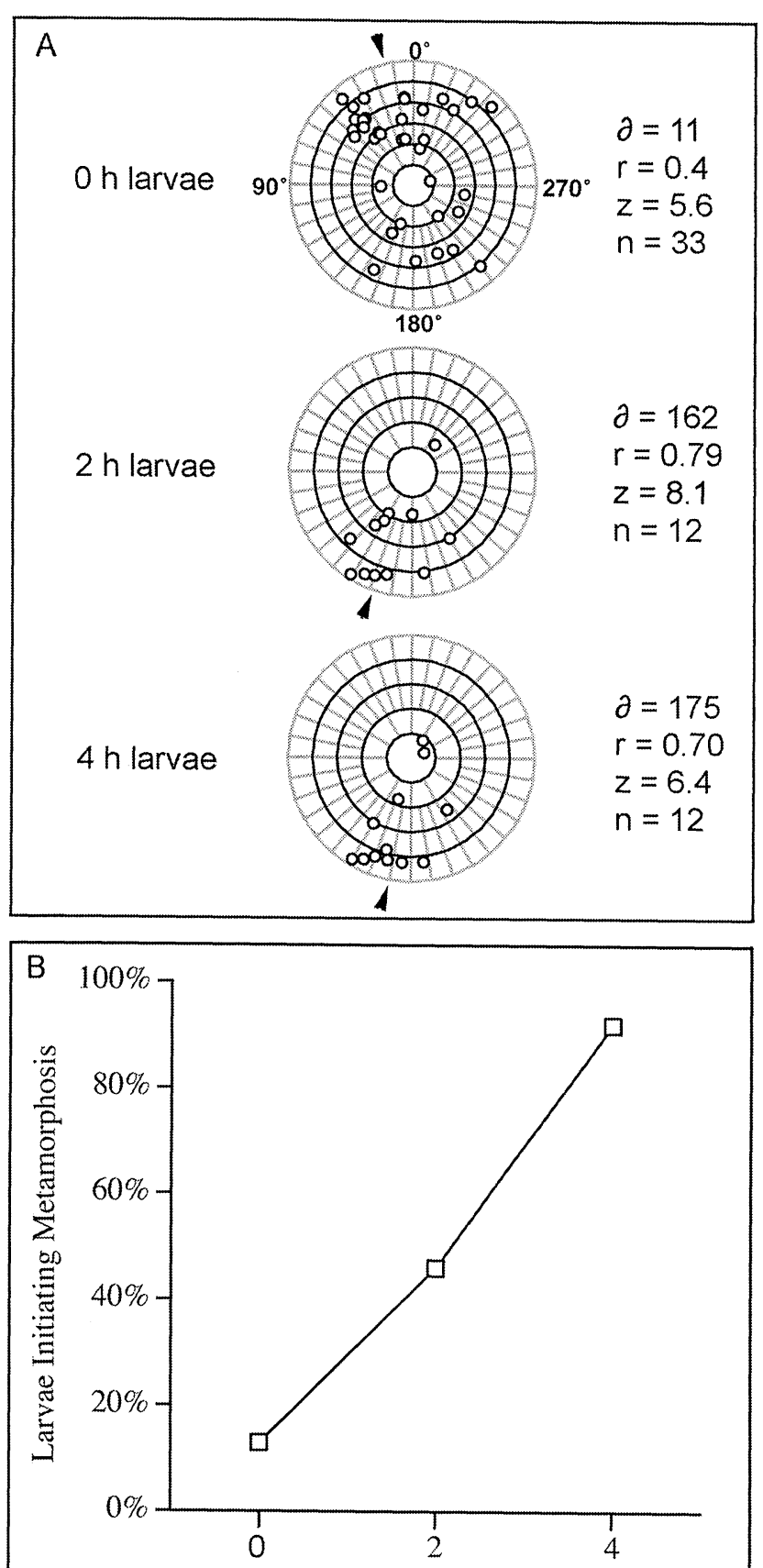

Swimming Duration (h)

Fig. 2. Florida experiment. (A) Phototaxis of larvae of Bugula neritina at release $(0 \mathrm{~h}), 2 \mathrm{~h}$, and $4 \mathrm{~h}$. The light source is at $0^{\circ}$, the brightest part of the chamber; $180^{\circ}$ is the darkest part of the chamber. " $\delta$ " is the mean angle of deviation from the light source. " $r$ " is a measure of dispersion which ranges from 0 (totally random) to 1 (no dispersion; i.e., all larvae swam to the same exact point). " $\mathrm{z}$ " is a statistic that is normally distributed and is used to determine if the mean angle of deviation $(\delta)$ is significant $(z>2.90$ is significant at not find any repeatable "pipette effect," corroborating Pires \& Woollacott's (1997) observation with $B$. neritina.

\section{Results}

\section{Interdependence of sign of phototaxis and onset of metamorphic competence}

In the experiments performed in Florida, where individual larvae were followed, larvae of Bugula neritina were photopositive on release and became photonegative by $2 \mathrm{~h}$ of swimming and remained so through the $4 \mathrm{~h}$ time period of the experiment (Fig. 2). For newly released larvae, the mean angle of deviation from the light source $(\delta)$ was $11^{\circ}$ and the distribution of larvae in the chamber was significantly different from random $(\mathrm{z}=5.6, \mathrm{p}=.01)$. Despite a significant photopositive distribution on release, a few larvae appeared photoneutral and some demonstrated a negative phototaxis. Of the newly released larvae, only $13 \%$ metamorphosed after $0.5 \mathrm{~h}$ of exposure to $10 \mathrm{mM}$ excess $\mathrm{KCl}$. Metamorphosis increased at $2 \mathrm{~h}$ and $4 \mathrm{~h}$ after release to $42 \%$ and $92 \%$, respectively.

In a separate set of experiments done in Hawaii, where percent metamorphosis of groups of larvae was followed, larvae behaved differently than in the Florida experiments on individual larvae. By the conclusion of $4 \mathrm{~h}$ in-group treatments, only slightly more than one half of the population of larvae switched from photopositive to photonegative. As such, $4 \mathrm{~h}$ after release there were some larvae that were photopositive and some that were photonegative in the treatment vessels. It was shown that photopositive larvae of $B$. neritina swimming for $4 \mathrm{~h}$ metamorphosed at values almost identical to larvae of the same age that were photonegative; however, both metamorphosed at levels much higher than control larvae which were $1 \mathrm{~h}$ old (Kruskal-Wallis Test; $\mathrm{p}=.0001$ ) (Fig. 3B). In a second experiment, young larvae $(<0.5 \mathrm{~h})$, prematurely made photonegative by exposure to $10^{-5} \mathrm{M} 5 \mathrm{HT}$, metamorphosed at relatively low rates not significantly different than young larvae that were photopositive (One-way ANOVA: $\quad \mathrm{df}=3 ; \mathrm{S}=502 ; \quad \mathrm{MS}=167 ; \mathrm{F}=78.33$, $\mathrm{p}=.0001$; Fisher's PLSD $\mathrm{p}=.53$ ) (Fig. 3A). Addition-

$\leftarrow$

$\mathrm{p}=.05)$. " $\mathrm{n}$ " is the number of larvae tested at each time. In cases where 2 larvae traveled to the same point in the chamber, the number of data points on a graph will be fewer than " $n$ ". In all cases, the mean angle of deflection ( $\delta$ ) was significant and is denoted by arrowheads. (B) Percentage of larvae from Fig. 2A that initiated metamorphosis within 30 min after phototaxis measurement. 
ally, in the absence of $10 \mathrm{mM} \mathrm{KCl}$, metamorphosis in the presence of $10^{-5} \mathrm{M} 5 \mathrm{HT}$ was identical to seawater controls (Fig. 3A).

\section{Ontogeny of phototaxis and metamorphic competence in $B$. simplex and $B$. stolonifera}

Bugula simplex and B. stolonifera were similar to each other in the pattern of ontogeny of phototaxis and metamorphic competence over their larval swimming period. When fates of individual larvae are evaluated, both species have larvae that, when data on individuals are combined as a population, do not demonstrate discernibly positive or negative phototactic behavior on release. By $2 \mathrm{~h}$ of larval swimming, however, larvae of both species were photonegative and remained so for the $10 \mathrm{~h}$ duration of the experiment (Fig. 4). On release, $\sim 75 \%$ of larvae of $B$. simplex metamorphosed in response to $10 \mathrm{mM}$ excess $\mathrm{KCl}$ and the percentage of metamorphosing larvae gradually increased to $\sim 95 \%$ throughout the duration of the experiment (Fig. $5)$. In general, a similar trend in the ontogeny of metamorphic competence was observed for B. stolonifera; $65 \%$ of the larvae metamorphosed on release, and by $4 \mathrm{~h}$ almost all the individuals were metamorphosing (Fig. 5). Additionally, more than $50 \%$ of larvae in both species lost metamorphic competence after $24 \mathrm{~h}$ of larval swimming, and by $36 \mathrm{~h}$ about $75 \%$ of larvae of $B$. simplex lost competence and $95 \%$ of $B$. stolonifera did not metamorphose (Fig. 5).

\section{Discussion}

Most measurements of larval phototaxis reported in the older literature were conducted under laboratory conditions using concentrated beams of white light. Forward (1988) suggested that light sources of this fashion do not emulate the diffuse light encountered under natural conditions and that many of the positively phototactic responses reported for larvae may be artifacts. In fact, larvae of the estuarine crab Rhithropanopeus harrisi are strongly photopositive under concentrated beams of light (Forward 1974), but show no response in conditions that more closely mimic natural conditions (Forward 1986). In species with relatively large larvae $(\sim 1 \mathrm{~mm})$, direct field observations of behavior are beneficial to resolving these conflicts (e.g., Olson 1985; Young 1986; Barile et al. 1994). However, laboratory observations are still required for species with relatively small larvae $(<0.5 \mathrm{~mm})$. To avoid this potential problem, we used diffuse light in all our experiments.
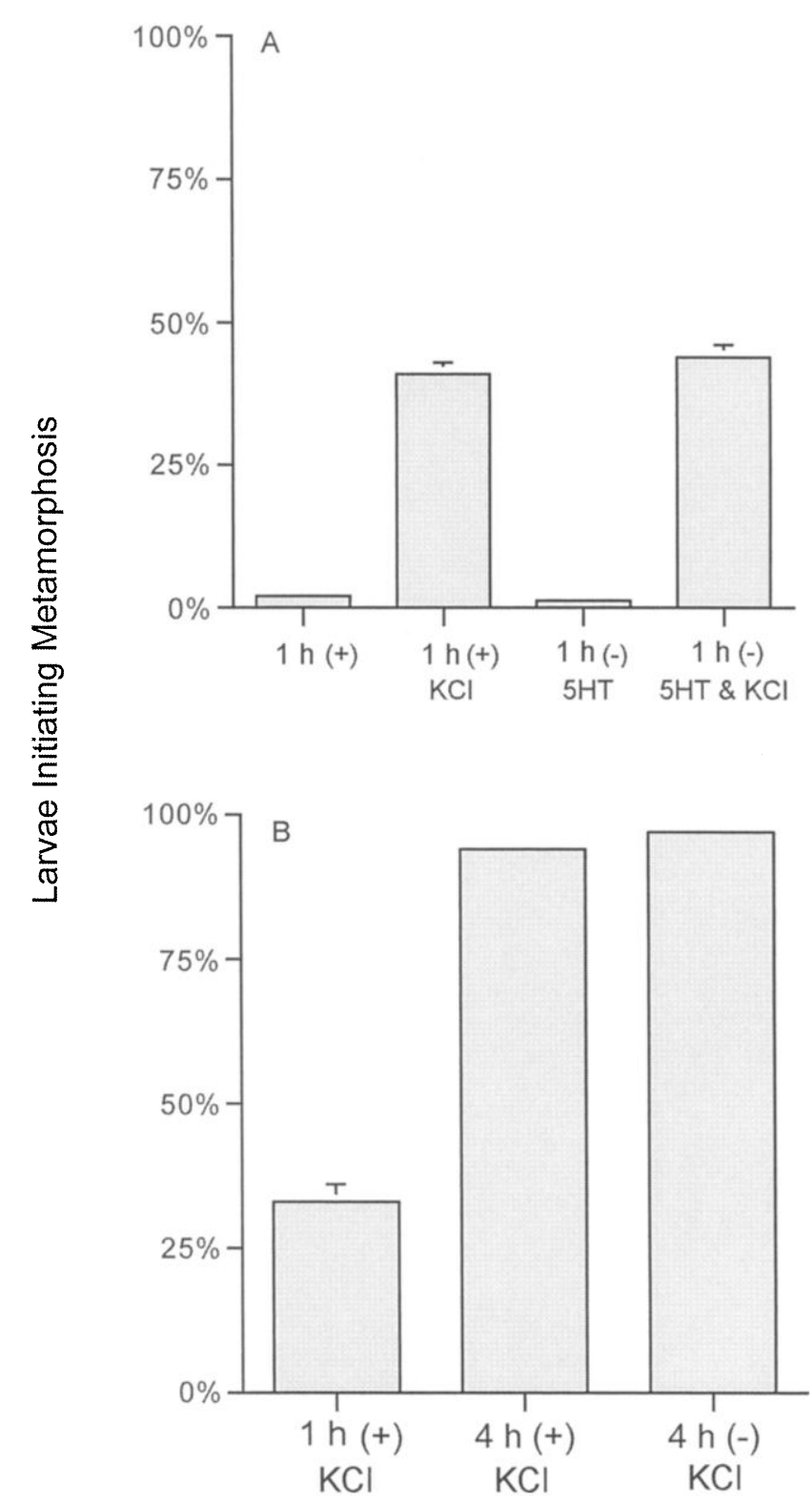

Treatment

Fig. 3. Hawaii experiment. (A) Metamorphic competence of 1-h-old larvae of $B$. neritina artificially made photonegative (-) using bath-applied 5HT at $10^{-5} \mathrm{M} ; \mathrm{n}=15$. (B) Metamorphic competence of 4-h-old larvae which were photopositive $(+)$ and photonegative $(-)$ induced to metamorphose with $10 \mathrm{mM}$ excess $\mathrm{KCl}$ in seawater. Error Bars=1 SE. Error bars not shown are too small to be resolved; $n=45$.

\section{Interdependence of sign of phototaxis and onset of metamorphic competence}

In our experiments we found a concomitant shift in the sign of phototaxis (i.e., positive to negative) and the onset of metamorphic competence (Fig. 2). By 4 $h$ of larval swimming, almost $100 \%$ of the larvae of 

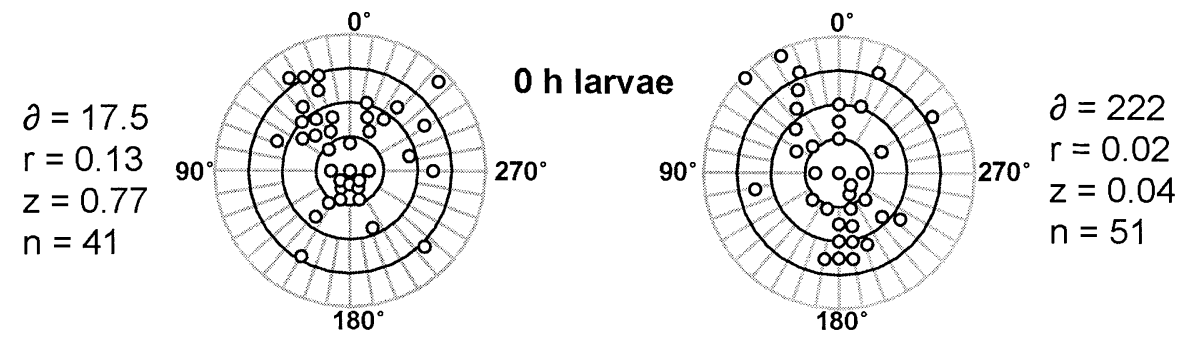

$$
\begin{aligned}
& \partial=173 \\
& r=0.61 \\
& z=16.9 \\
& n=44
\end{aligned}
$$

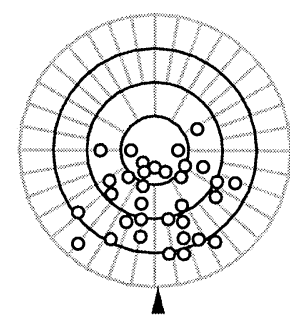

$2 \mathrm{~h}$ larvae

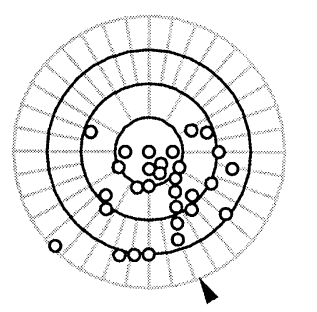

$$
\begin{aligned}
& \partial=202 \\
& r=0.64
\end{aligned}
$$$$
z=19.5
$$$$
\mathrm{n}=46
$$

$$
\begin{aligned}
& \partial=173 \\
& r=0.61 \\
& z=18.9 \\
& n=44
\end{aligned}
$$

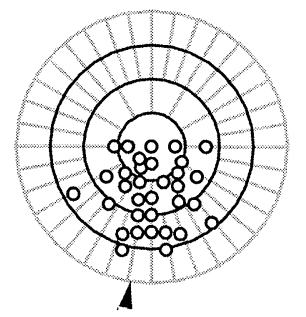

$4 \mathrm{~h}$ larvae

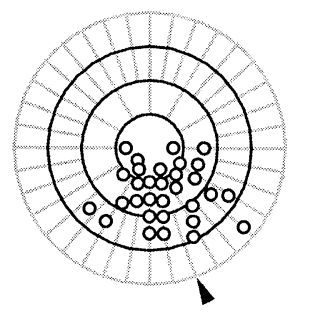

$$
\begin{aligned}
& \partial=200 \\
& r=0.72 \\
& z=24.4 \\
& n=46
\end{aligned}
$$

$$
\begin{aligned}
& \partial=212 \\
& r=0.59 \\
& z=14.3 \\
& n=40
\end{aligned}
$$

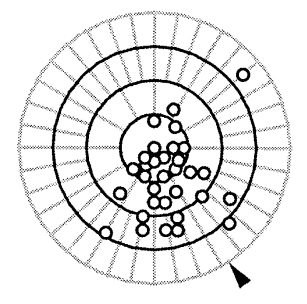

$6 \mathrm{~h}$ larvae

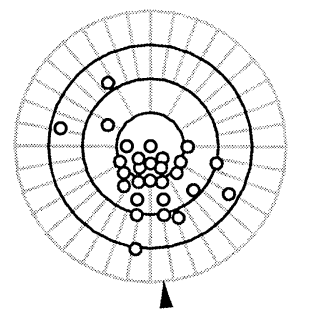

$$
\begin{aligned}
& \partial=187 \\
& r=0.70 \\
& z=21.6 \\
& n=43
\end{aligned}
$$

$$
\partial=210
$$

$r=0.63$

$z=13.0$

$\mathrm{n}=32$

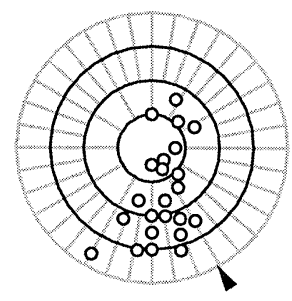

8 h larvae

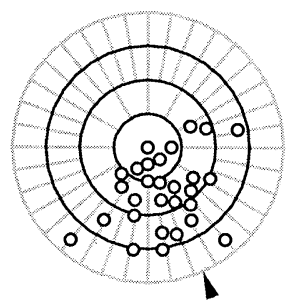

$$
\partial=205
$$

$r=0.80$

$z=25.2$

$\mathrm{n}=39$

$$
\begin{aligned}
& \partial=179 \\
& r=0.64 \\
& z=17.0 \\
& n=41
\end{aligned}
$$
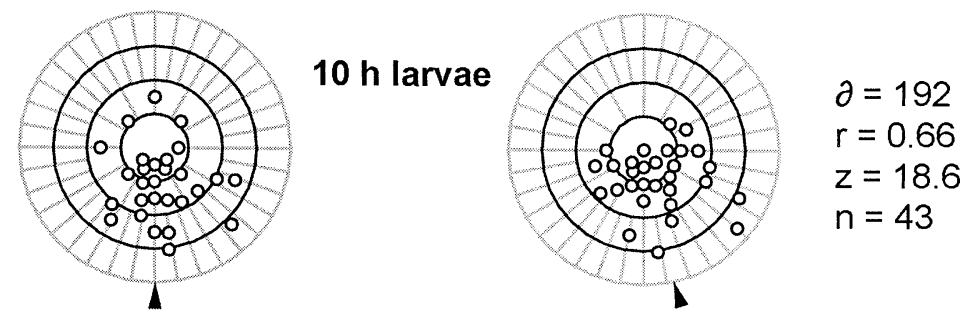

Fig. 4. Cambridge experiment. Ontogeny of larval phototaxis in $B$. simplex and $B$. stolonifera at $2 \mathrm{~h}$ time intervals. The light source is at $0^{\circ}$, the brightest part of the chamber; $180^{\circ}$ was the darkest part of the chamber. " $\delta$ " is the mean angle of deviation from the light source. Statistics as in Fig. 2. Significant mean angles are denoted with solid arrow heads.

Bugula neritina were metamorphosing in response to $10 \mathrm{mM}$ excess $\mathrm{KCl}$. As a population, the larvae demonstrated a simultaneous shift from positive to negative phototaxis, although a portion of the individuals tested did not show a photopositive response on re- lease. Larvae of another bryozoan, Celleporella hyali$n a$, demonstrated a similar pattern in the onset of competence and a change from positive to negative phototaxis (Ramirez \& Cancino 1991). Our data also show that the aged $(4 \mathrm{~h})$ larvae that are photopositive 


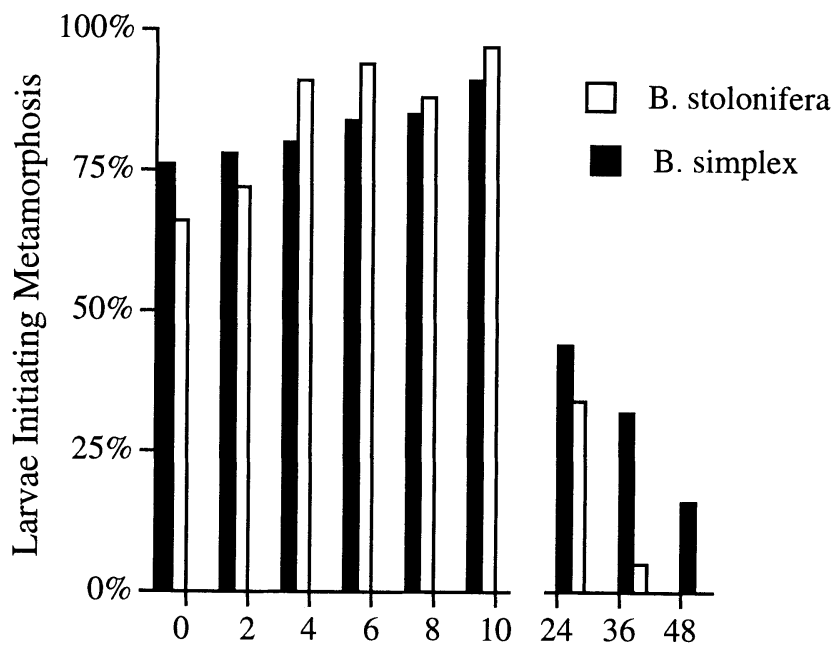

Swimming Duration (h)

Fig. 5. Percentage of larvae shown in Fig. 4 that initiated metamorphosis within $30 \mathrm{~min}$ of the measurement of larval photoresponse. Competence was tested at 24,36 , and $48 \mathrm{~h}$, although phototaxis was not measured at these times.

metamorphose at levels similar to aged larvae that are photonegative (Fig. 3B); young larvae, prematurely made photonegative with exposure to 5HT (serotonin), do not metamorphose at levels higher than young larvae that are photopositive (Fig. 3A). Thus, it appears the shift in phototaxis and metamorphic competence in larvae of $B$. neritina are two independent developmental processes that may have been synchronized temporally through selective processes, acting to time the onset of competence with the encountering of a suitable site for metamorphosis. Quantitative genetic analysis of the variability and heritability of these traits would be needed to meaningfully address this explanation (Hadfield 1998).

It is not known if the timing of the onset of competence in larvae of bryozoans is similar when assayed using $\mathrm{KCl}$ versus natural inducers. In the gastropod Crepidula fornicata, larvae become responsive to $\mathrm{KCl}$ and natural inducers simultaneously (Pechenik \& Gee 1993). On the other hand, Pechenik et al. (1995) found that larvae of the gastropod Phestilla sibogae become responsive to $\mathrm{KCl}$ later in development than they do to the natural inducer. Thus, it appears the underlying mechanisms for induction of metamorphosis and the sites of $\mathrm{KCl}$ action can differ between species (see Woollacott \& Hadfield 1996 for discussion).

\section{Ontogeny of phototaxis and metamorphic competence in $B$. simplex and $B$. stolonifera}

Our data demonstrate that larvae of $B$. simplex and $B$. stolonifera have similar patterns in the ontogenies of phototaxis and metamorphic competence (Figs. 4, 5). As populations, larvae of neither species showed positive phototaxis on release, but both species clearly became negative as they aged. It is clear that a significant portion of the larvae are metamorphically competent on release in these species $(60 \%$ and $75 \%$ for $B$. simplex and $B$. stolonifera, respectively) and that after relatively short larval swimming periods, $>90 \%$ of the larvae initiate metamorphosis. From these data, we conclude that metamorphic competence and phototaxis are also not physiologically linked (i.e., coupled) in larvae of these species, because young larvae metamorphosed regardless of their apparent response to light. In addition, the $\sim 30 \%$ of larvae that did not metamorphose immediately after release showed positive and negative phototaxes. If these processes were linked, one would expect that larvae that did not metamorphose would have been photopositive, but this outcome was not observed. Thus, in these species, as in $B$. neritina, the data suggest the shift in phototaxis and the onset of metamorphic competence are independent developmental processes that have been temporally synchronized. A similar result was found by Miller \& Hadfield (1986) with veliger larvae of the gastropod Phestilla sibogae. For a population of larvae, they found an inverse relationship between the onset of metamorphic competence and a change from positive phototaxis. However, in another experiment, they found no significant difference in the number of individuals that metamorphosed at the lighted end of a vertical column of seawater compared to the dark end, suggesting that the larvae do not become photonegative; instead, Miller \& Hadfield (1986) suggested that the larvae of $P$. sibogae are initially photopositive and then become photo-indifferent. Regardless, there exists an apparent synchronization between the time in development when larvae in at least two phyla change sign of phototaxis and when they become competent to metamorphose.

Acknowledgments. We thank Edward Seling (Harvard University) for his expert technical assistance with experiments on Bugula simplex and B. stolonifera and for his thoughtful discussions throughout the duration of this project. Edie Widder and Craig Young (Harbor Branch Oceanographic Institute) provided invaluable suggestions for the design and construction of the phototaxis apparatus. Sherry Reed, Hugh Reichardt, and Mary Rice offered assistance and advice during field work conducted by D.E. Wendt at the Smithsonian Marine Station at Fort Pierce, Fort Pierce, Florida. Laboratory space in Hawaii for R.M. Woollacott was made available through the kindness of Michael Hadfield (Director, Kewalo Marine Laboratory, University of Hawaii). Scott Schellhammer helped with collecting B. neritina in Hawaii. Much appreciation goes to Edward Enos at Marine Biolog- 
ical Laboratory and "Pinky" in Woods Hole, Massachusetts for generously allowing us to collect animals from their respective facilities. We thank Professor Michael Hadfield and an anonymous reviewer for helpful comments on the manuscript. Portions of this research were supported by a Smithsonian Fellowship and by a Grant-in-Aid of Research from Sigma Xi to D.E. Wendt. This is contribution number \# 453 to the Smithsonian Marine Station at Fort Pierce.

\section{References}

Barile PJ, Stoner AW, \& Young CM 1994. Phototaxis and vertical migration of the queen conch (Strombus gigas Linné) veliger larvae. J. Exp. Mar. Biol. Ecol. 183: 147-162.

Clarke GL 1970. Light conditions in the sea in relation to the diurnal vertical migrations of animals. In: Proc. International Symp. on Biological Sound Scattering in the Ocean, pp. 41-48. Maury Center for Ocean Science, Department of the Navy; Washington, DC.

Coon SL, Frit WK, \& Bonar DB 1990. Competence and delay of metamorphosis in the Pacific oyster, Crassostrea gigas (Thunberg). Mar. Biol. 106: 379-387.

Crisp DJ 1974. Factors influencing the settlement of marine invertebrate larvae. In: Chemoreception in Marine Organisms. Grant PT \& Mackie AM, eds., pp. 177-265. Academic Press, New York.

Cronin TW \& Forward RB, Jr 1979. Tidal vertical migrations: an endogenous rhythm in estuarine crab larvae. Science 205: 1020-1022.

Dirnberger JM 1993. Dispersal of larvae with a short planktonic phase in the polychaete Spirorbis spirillum (Linnaeus). Bull. Mar. Sci. 52: 898-910.

Forward RB, Jr 1974. Negative phototaxis in a crustacean larvae: possible functional significance. J. Exp. Mar. Biol. Ecol. 16: 11-17.

1986. A reconsideration of the shadow response of a larval crustacean. Mar. Behav. Physiol. 12: 99-113.

1988. Diel vertical migration: zooplankton photobiology and behavior. Oceanog. Mar. Biol. Ann. Rev. 26: 361-393.

Gibson G 1995. Why be choosy? Temporal changes in larval sensitivity to several naturally-occuring metamorphic inducers in the opisthobranch Haminaea callidegenita. J. Exp. Mar. Biol. Ecol. 194: 9-24.

Hadfield MG 1984. Settlement requirements of molluscan larvae: new data on chemical and genetic roles. Aquaculture. 39: 283-298.

1998. The DP Wilson Lecture. Research on settlement and metamorphosis of marine invertebrate larvae: past, present, future. Biofouling 12: 9-29.

McDougall KD 1943. Sessile marine invertebrates at Beaufort, North Carolina. Ecol. Monogr. 13: 321-374.

Miller SE \& Hadfield MG 1986. Ontogeny of phototaxis and metamorphic competence in larvae of the nudibranclPhestilla sibogae Bergh (Gastropoda: Opisthobranchia). J. Exp. Mar. Biol. Ecol. 97: 95-112.

$\rightarrow$ Olson RR 1985. The consequences of short-distance larval dispersal in a sessile marine invertebrate. Ecology 66: 30-39.

Pawlik JR 1992. Chemical ecology of marine invertebrates. Oceanogr. Mar. Biol. Ann. Rev. 30: 273-335.

Pechenik JA 1990. Delayed metamorphosis of benthic marine invertebrates: Does it occur? Is there a price to pay? Ophelia 32: 63-94.

Pechenik JA \& Gee CC 1993. Onset of metamorphic competence in larvae of the gastropod Crepidula fornicata (L.), judged by a natural and artificial cue. J. Exp. Mar. Biol. Ecol. 167: 59-72.

Pechenik JA \& Qian P-Y 1998. Onset and maintenance of metamorphic competence in the marine polychaete $\boldsymbol{H y}$ droides elegans Haswell in response to three chemical cues. J. Exp. Mar. Biol. Ecol. 226: 51-74.

Pechenik JA, Hadfield MG, \& Eyster LS 1995. Assessing whether larvae of the opisthobranch gastropod Phestilla sibogae Bergh become responsive to three chemical cues at the same age. J. Exp. Mar. Biol. Ecol. 191: 1-17.

Pechenik JA, Hammer K, \& Weise C 1996. The effect of starvation on acquisition of competence and postmetamorphic performance in the marine prosobranch gastropod Crepidula fornicata (L.). J. Exp. Mar. Biol. Ecol. 199: 137-152.

Pires A \& Woollacott RM 1983. A direct and active influence of gravity on the behavior of a marine invertebrate larva. Science 220: 731-733.

1997. Serotonin and dopamine have opposite effects on phototaxis in larvae of the bryozoan Bugula neritina. Biol. Bull. 192: 399-409.

Ramirez CC \& Cancino JM 1991. Responses to light and settlement behaviour of Celleporella hyalina (L.) (Bryozoa). Revista Chilena Historia Natural 64: 29-35.

Ryland JS 1960. Experiments on the influence of light on the behaviour of polyzoan larvae. J. Exp. Biol. 37: 783-800.

Sulkin SD 1984. Behavioral basis of depth regulation in the larvae of the brachyuran crabs. Mar. Ecol. Prog. Ser. 15: 181-205.

Thorson GL 1964. Light as an ecological factor in the dispersal and settlement of larvae of marine bottom invertebrates. Ophelia 1: 167-208.

Wendt DE 1996. Effect of larval swimming duration on success of metamorphosis and size of the ancestrular lophophore in Bugula neritina (Bryozoa). Biol. Bull. 191: 224-233.

$\rightarrow$ Wendt DE \& Woollacott RM 1995. Induction of larval settlement by $\mathrm{KCl}$ in three species of Bugula (Bryozoa). Invertebr. Biol. 114: 345-351.

Woollacott RM 1984. Environmental factors in bryozoan settlement. In: Marine Biodeterioration: an Interdisciplinary Study. Costlow JD \& Tipper RC, eds., pp. 149-154. Naval Institute Press, Annapolis, Maryland.

Woollacott RM \& Hadfield MG 1996. Induction of metamorphosis in larvae of a sponge. Invert. Biol. 115: 257-262.

Young CM 1986. Direct observations of field swimming be- 
havior in larvae of the colonial ascidian Ecteinascidia turbinata. Bull. Mar. Sci. 39: 279-289.

1995. Behavior and locomotion during the dispersal phase of larval life. In: Ecology of Invertebrate Larvae. McEdward L, ed., pp. 249-277. CRC Press, Boca Raton, Florida.

Young CM \& Chia F-S 1982. Ontogeny of phototaxis during larval development of the sedentary polychaete, Serpula vermicularis (L.) Biol. Bull. 162: 457-468.
Zaslow RB-D \& Benayahu Y 1996. Longevity, competence and energetic content in planulae of the soft coral Heteroxenia fuscescens. J. Exp. Mar. Biol. Ecol. 206: 55-68.

Zar JH 1996. Biostatistical Analysis, 3rd Edition. PrenticeHall, Inc.; Englewood Cliffs, New Jersey. 662 pp.

Zimmer RL \& RM Woollacott 1977. Metamorphosis, ancestrulae, and coloniality in bryozoan life cycles. In: Biology of Bryozoans. Woollacott RM \& Zimmer RL, eds., pp. 91-142. Academic Press, New York.

\title{
34th European Marine Biology Symposium
}

\author{
13-17 September 1999 \\ Ponta Delgada - Azores - Portugal \\ University of the Azores/Department of Biology
}

Topics

- Ecology and Evolution on Island Shores

- The Open Ocean - The Deep Ocean

- Open Session (other topics)

Deadline for abstracts: May 31

Web Site: http://www.uac.pt/db/embs34

34th EMBS Organising Commission

Secretariado EMBS 34, Departamento de Biologia

Seç̧ão de Biologia Marinha, Universidade dos Açores

Rua da Mãe de Deus, 589502 Ponta Delgada CODEX

Tel.: + 35196653044 (ext.1237) $\quad$ Fax.: + 35196653455 E-mail: embs34@ alf.uac.pt 